\title{
Instituto de Previdência dos Servidores do Município de Nilópolis e os Problemas Acarretados pela Rotatividade dos Servidores que Atuam no Setor
}

\section{Resumo}

A rotatividade de pessoal é uma das grandes dificuldades encontradas pelo serviço público. A causa desse problema pode estar relacionada a fatores como: remuneração e recompensa, rotinização, conflitos, satisfação/insatisfação dos colaboradores, motivação/demotion, questões políticas, entre outros. É nessa rotatividade de pessoal que se problematiza o presente estudo que tem por objetivo apontar medidas que ajudem a solucionar o problema da rotatividade dos servidores comissionados do Instituto de Previdência do município Nilópolis, propondo soluções que possam contribuir com a solução do problema encontrado naquele instituto. Procurou-se com o estudo conhecer as possíveis causas para a saída dos servidores, motivo causador da rotatividade, de modo a propor medidas que possam auxiliar em uma revisão dos processos e políticas de organização e gestão daquele instituto, combatendo, desse modo, a rotatividade e os custos operacionais dela decorrentes. Uma das medidas propostas para minimizar a rotatividade de pessoal no instituto em análise é a elaboração de estratégias que ajudem a reconhecer as motivações para a saída dos servidores, pois a partir desse conhecimento é possível elaborar medidas de melhorias nos processos de gestão e organização do referido instituto, de modo a criar políticas de valorização e incentivo para que estes profissionais desejem permanecer no quadro de servidores, quando isso se fizer possível.

Palavras-chave: dificuldades. Serviço Público. Medidas. Soluções.

Institute Of Social Security for the Servants of the Municipality of Nilópolis and the problens caused by the Turnover of Servers in the Sector

\section{ABSTRACT}

Personnel turnover is one of the major difficulties encountered by the public service. The cause of this problem may be related to factors such as: remuneration and reward, routine, conflicts, employee satisfaction / dissatisfaction, motivation / demotivation, political issues, among others. It is in this staff turnover that the present study is problematized, which aims to point out measures that help to solve the problem of the turnover of commissioned employees of the Social Security Institute in the municipality of Nilópolis, proposing solutions that can contribute to the solution of the problem found in that institute. The study sought to find out the possible causes for the departure of the servers, a reason that causes turnover, in order to propose measures that can assist in a review of the processes and policies of organization and management of that institute, thus combating turnover and the resulting operating costs. One of the measures proposed to minimize staff turnover at the institute under analysis is the development of strategies that help to recognize the motivations for leaving the servers, as from this knowledge it is possible to develop measures to improve the management and organization processes of the aforementioned institute in order to create valuation and incentive policies so that these professionals wish to remain on the staff, when this is possible.

Keywords: Turnover. Difficulties. Public service. Measures. Solutions. 
Instituto de Seguridad Social para los Servidores del Municipio de Nilópolis y los problemas que genera la Rotación de Servidores en el Sector

\section{Resumen}

La rotación de personal es una de las principales dificultades con las que se encuentra el servicio público. La causa de este problema puede estar relacionada con factores como: remuneración y recompensa, rutina, conflictos, satisfacción / insatisfacción de los empleados, motivación / degradación, temas políticos, entre otros. Es en esta rotación de personal donde se problematiza el presente estudio, que tiene como objetivo señalar medidas que ayuden a solucionar el problema de la rotación de empleados contratados del Instituto de la Seguridad Social en el municipio de Nilópolis, proponiendo soluciones que puedan contribuir a la solución. del problema encontrado en ese instituto. El estudio buscó conocer las posibles causas de la salida de los servidores, motivo que provoca la rotación, con el fin de proponer medidas que puedan ayudar en una revisión de los procesos y políticas de organización y gestión de ese instituto, combatiendo así la rotación. y los costos operativos resultantes. Una de las medidas propuestas para minimizar la rotación de personal en el instituto analizado es el desarrollo de estrategias que ayuden a reconocer las motivaciones para dejar los servidores, ya que a partir de este conocimiento es posible desarrollar medidas para mejorar los procesos de gestión y organización de los mismos. instituto, con el fin de generar políticas de valoración e incentivos para que estos profesionales deseen permanecer en la plantilla, cuando sea posible.

Palabras clave: dificultades. Servicio Público. Medidas. Soluciones.

\section{Objetivo da pesquisa}

Apesar de haver uma rica literatura empírica sobre rotatividade em organizações privadas (Moynihan \& Pandey, 2008), estudos no setor público parecem ser incipientes.

Nesse contexto, esta pesquisa torna-se significativa dado que não se encontrou nenhuma pesquisa bibliométrica sobre o tema de Rotatividade no Serviço Público, evidenciando uma lacuna de pesquisa que deve ser suprida. A análise bibliométrica se baseia na evidenciação quantitativa dos parâmetros de um conjunto definido de artigos sobre um determinado tema. Para mensurar, interpretar e avaliar os resultados obtidos das buscas, pesquisadores recorrem a técnicas bibliométricas, que são análises quantitativas com fins de mensurar a produção e disseminação científica (Araújo, 2006). Segundo El-Maamiry e Ghauri (2013), a bibliometria é utilizada por várias áreas da ciência e emprega indicadores quantitativos, como: número de artigos, número de citações, coautoria e estruturais (copublicações, índice de afinidade, redes científicas medidas por citações, ocorrência de palavras e técnicas de representação visual). Para composição desta pesquisa bibliométrica, realizou-se 
um levantamento de artigos científicos revisados por pares publicados entre os anos de $2006 \mathrm{e}$ 2017 em periódicos nacionais e internacionais por meio de busca no Portal de Periódicos da Capes, SPELL e Web of Science.

Um dos grandes problemas encontrados no setor público é a rotatividade de servidores que atuam em cargos comissionados, de livre nomeação e exoneração, pois em grande parte das organizações publicas o trabalho que vem sendo desenvolvido por estes servidores nem sempre são vistos com bons olhos e quando existe mudança na gestão, geralmente estes são destituídos do cargo, outro fato relevante acontece quando estes são descartados ou menosprezados pelo novo servidor que irá atuar na mesma função. Isso faz com que o trabalho que vinha sendo desenvolvido seja interrompido, prejudicando, de certa forma, não apenas o setor em si, mas também o munícipe que é usuário dos serviços públicos.

Esse tem sido um problema recorrente no Instituto de Previdência dos Servidores do município de Nilópolis, uma autarquia com autonomia administrativa e financeira, onde os servidores comissionados são maioria e, de modo geral, com a mudança da gestão municipal, de quatro em quatro anos, ocorrem mudanças no quadro de servidores que atuam no setor.

De modo a atingir sua meta e minimizar os prejuízos advindos da rotatividade dos servidores, o referido instituto tem se utilizado do controle interno municipal como uma ferramenta fundamental para atingir resultados positivos. No entanto, mesmo que medidas venham sendo tomada, a rotatividade de servidores comissionados continua ocorrendo, o que reflete, negativamente, no desempenho e na atuação dos novos servidores comissionados que vão sendo contratados e que muitas vezes não tem o preparo e a capacitação adequada para exercer o cargo, acarretando, dessa forma, falhas que são sentidas por toda a administração e pela população que se utiliza dos serviços públicos.

Frente às perspectivas apresentadas, a presente pesquisa se problematiza em refletir sobre a rotatividade dos servidores comissionados do Instituto de Previdência de Nilópolis, provocada pela interferência política na gestão, e pela dificuldade de especialização e adaptação destes, às normas e procedimentos da instituição prevista em seus manuais.

O controle interno do município de Nilópolis tem procurado soluções viáveis, que serão apresentadas no decorrer da presente pesquisa, para solucionar o problema da rotatividade dos servidores lotados no Instituto de Previdência dos Servidores do referido município. Soluções estas que visam minimizar os prejuízos provocados pela rotatividade dos servidores comissionados.

No sentido de tentar compreender as medidas que já vem sendo tomadas e buscar novas e possíveis soluções, o presente estudo teve como objetivo geral: apontar medidas que ajudem a solucionar o problema da rotatividade dos servidores comissionados do Instituto de Previdência do município Nilópolis, produzir efeitos positivos e propor soluções que podem contribuir com a solução do problema encontrado naquele instituto. E tem como objetivos específicos: verificar o modo como a rotatividade dos servidores comissionados tem 


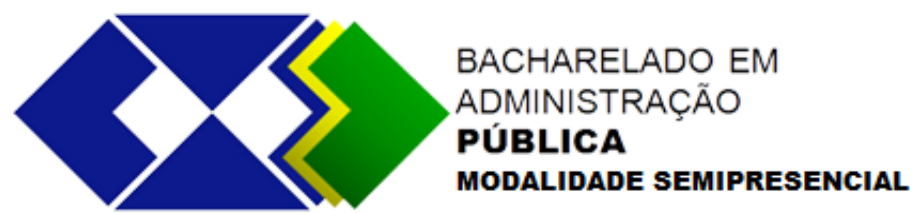

prejudicado as atividades do Instituto de Previdência do município de Nilópolis; entender os motivos que levam à rotatividade e os problemas que esta traz; propor soluções que possam ajudar/contribuir com a solução do problema.

Um estudo com essa envergadura se justifica baseado em três dimensões que são a social, por se tratar de um tema atual considerando as grandes transformações no campo político, econômico e social, o ritmo de trabalho cada vez mais acelerado e a inclusão de novas tecnologias que, consequentemente, trazem novos desafios à retenção de servidores nas organizações; a organizacional, que na medida em que contribui para conhecer os antecedentes da rotatividade e a organização consiga alocar melhor, estimular, criar condições satisfatórias visando a reter essas pessoas, que são um de seus principais recursos, ou ainda, propôs ações que minimizem os impactos de elevados índices de rotatividade; e acadêmica: tendo em vista a produção nacional de um novo estudo sobre rotatividade e IR, que, apesar de uma rica literatura empírica baseada em estudos de organizações privadas (Moynihan \& Pandey, 2008), ainda é incipiente no setor público e no fato de que a rotatividade gera prejuízos ao setor público por motivos como a interrupção de projetos, sobrecarga de trabalho para os servidores que permanecem, gastos desnecessários, entre outros.

\section{Enquadramento teórico}

Um dos primeiros conceitos que merece destaque é o de administração pública que, segundo Garcia e Araújo (2012), é a gestão de bens e de interesse da sociedade ao que tange o âmbito federal, estadual ou municipal, em consonância com os preceitos do direito e da moral, visando à manutenção do bem e interesse comum. No âmbito do Direito Administrativo, a Administração Pública tem por desígnio tanto pessoas quanto órgãos governamentais, como a atividade administrativa em si mesma, Bergue (2010, pag.18) afirma que:

Uma definição possível para a Gestão de pessoas no setor público é: esforço orientado para o suprimento, a manutenção, e o desenvolvimento de pessoas nas organizações públicas, em conformidade com os ditames constitucionais e legais, observadas as necessidades e condições do ambiente em que se inserem.[...] Nesse contexto, a gestão de pessoas envolve um conjunto de ações preliminares de planejamento das necessidades mútuas entre organização e as pessoas, o arranjo dos recursos necessários à satisfação dessas necessidades, seguido dos esforços de direção desse conjunto, orientados pelo vetor resultante do produto dos objetos institucionais e individuais constantemente balizado 
pelo cotejo entre o desempenho efetivo e previsto com vistas as correções de curso do processo.

Segundo informações de Mazza (2019), a administração pública brasileira é organizada e dividida na forma de administração pública direta e indireta. A administração pública direta também conhecida como administração centralizada é composta pelos entes que integram de forma indivisível e autônoma a federação, sendo eles a União, os estados, os territórios, o distrito federal e os municípios sendo estes dotados de natureza jurídica de direito público.

A administração pública indireta, por sua vez, é composta por entidades que, por meio de descentralização de competências do governo, foram criadas para desempenhar papéis nos mais variados setores da sociedade e prestar serviços à população. Essas entidades possuem personalidade jurídica própria (CNPJ), e, muitas vezes, recursos próprios, provenientes de atividades que geram receitas.

O primeiro exemplo são as autarquias. Elas são criadas por meio de lei e prestam serviços à população de forma descentralizada, nas mais diferentes áreas. Um exemplo de autarquia é o INSS (Instituto Nacional de Seguridade Social), hoje vinculado ao Ministério do Desenvolvimento Social e Agrário. O INSS atende aos aposentados e pensionistas cobertos pela previdência social e é responsável pelo benefício a milhões de cidadãos, bem como o Instituto de Previdência dos Servidores do município de Nilópolis, que é a autarquia vinculada a prefeitura municipal de Nilópolis que será o principal objeto deste estudo.

No que tange a sua natureza jurídica, os entes da administração pública direta possuem capacidade jurídica, ou seja, respondem judicialmente de forma objetiva pelos seus atos e de seus agentes na forma da lei e, gozam de determinadas prerrogativas, uma vez que, Ihes são conferidos certos privilégios em detrimentos de seu administrado tal como prazos processuais em dobro e imunidade tributária recíproca atuando em grau de superioridade valendo-se do principio administrativo se superioridade do interesse público (MAZZA, 2019).

Entretanto, ao se descentralizar, a administração pública direta cria-se entidades administrativas que compõem a administração pública indireta, sendo estas as autarquias, as fundações públicas, as empresas públicas e as sociedades de economia mista atuando na prestação de serviço público, ou mesmo na exploração de atividade econômica dotados de natureza jurídica de direito público ou de direito privado a depender de cada caso tipo constitutivo (MAZZA, 2019).

E um dos grandes problemas apresentados pela autarquia em análise é a rotatividade de pessoal (turnover) que trata da proporção de pessoas que se desligam de uma determinada organização em determinado intervalo de tempo, como ensinam Medeiros et al. (2010). O desligamento que leva a esta rotatividade encontra-se 
previsto na Lei 8.112/1990. A rotatividade de pessoal provocada por desligamento pode ser causada por redistribuição (no caso de cargo público), por exoneração ou vacância ou por posse de servidor em outro cargo não passível de acumulação, de acordo com a lei (BRASIL, 1990).

Segundo Chiavenato (2002, p.178), "A rotatividade de pessoal é expressa por meio de uma relação percentual entre as admissões e os desligamentos com relação ao número médio de participantes da organização, no decorrer de certo período de tempo".

A rotatividade é tratada de diversos pontos de vistas e com várias denominações conceituais. Na literatura, a expressão Rotatividade é citada de várias formas distintas, sendo usada com múltiplos sinônimos, quais sejam: Intenção de Rotatividade, Taxa de Rotatividade, Taxa Líquida de Substituição etc. À rotatividade é cotada como sendo o grau do número de trabalhadores que entram e saem dos postos de trabalho num dado intervalo de tempo. Em referência à intenção de rotatividade, esta indica a probabilidade de um indivíduo abandonar seu emprego em um determinado período de tempo (LINHARES, 2014).

Alguns motivos que podem levar à rotatividade de pessoal, segundo Maximiliano (2015) são: Remuneração e recompensas; Rotinização; Conflitos; Insatisfação dos colaboradores; Falta de motivação e, Processo de seleção e recrutamento.

Dentre os motivos/fatores acima elencados, a satisfação/insatisfação e a motivação se destacam como os mais pesquisados, podendo este descontentamento ser decorrente de vários elementos ligados ao ambiente de trabalho (LINHARES, 2014).

No que tange aos servidores públicos, os possíveis motivos para a rotatividade de pessoal estão ligados não apenas às expectativas do colaborador, mas também à sua visão da instituição e a vontade política envolvida, quando é o caso de servidores comissionados. Segundo Rodrigues (2015, p. 03): "[...] o servidor pondera pontos como o grau de influência de grupos de interesse na organização e se a ocupação das funções comissionadas ocorre por indicação política ou por mérito".

Segundo dados do DIEESE (2019), a taxa de rotatividade no serviço público, sem levar em conta aposentadorias ou morte, subiu de 6,6\% para 10,6\% entre os anos de 2011 e 2019. Percebe-se com isso que ainda que a estabilidade esteja garantida aos servidores públicos, a rotatividade continua acontecendo, acarretando altos custos e impactos financeiros.

Em relação aos índices de rotatividade, Campos e Malik (2018) afirmam que o ideal seria que houvesse uma variação próxima de $26 \%$ ou menor do que isso. Todavia, deve-se ficar atento quando esses índices atingem $50 \%$, pois esse percentual de rotatividade de pessoal pode comprometer a produtividade e a qualidade da organização.

No entanto, os autores afirmam que não há um número que defina um índice ideal de rotatividade que sirva para todos os tipos de organização, portanto, para que se analise se o índice é alto, baixo ou ideal deve-se levar em conta fatores como as especificidades de cada 
instituição, setor econômico em que atua contexto externo e interno, entre outros aspectos (RODRIGUES, 2015).

A rotatividade, em alguns casos, pode ser positiva, segundo Sancho et al. (2012), Eckert (2011) e Praça et al. (2012). Dentre os aspectos positivos estão:

- O fato de a instituição consegue reter os profissionais qualificados e substituir àqueles que, de modo geral, apresentam um desempenho inferior.

- A admissão de profissionais de carreira que podem propor novas soluções para problemas já existentes.

- Evitar a familiaridade entre servidores com suspeita de atividades ilícitas.

- Oxigenar o serviço público com novas ideias e competências ao agregar ao quadro que se mostrem mais qualificados e mais alinhados aos objetivos institucionais.

Quanto aos pontos negativos da rotatividade de pessoal, pode-se citar, segundo Eckert (2011) e Praça et al. (2012), Sancho (2012), Amaral e Lopes (2014), Rodrigues (2015):

- Perda da expertise de especialistas em alguns assuntos que já atuam no setor.

- Atrapalha na avaliação do desempenho funcional.

- Perda da produtividade.

- Diminuição da lucratividade.

- Perda do capital humano e intelectual.

- Aumento do risco de acidentes e de doenças ocupacionais provocada pelo aumento do volume de trabalho aos demais servidores.

- Impactos na motivação, comprometimento e na imagem da instituição.

Além disso, órgãos com maior rotatividade se mostram menos atraentes para pessoas mais qualificadas e capacitadas. Com isso, a eficiência organizacional pode ser prejudicada (COBÊRO; PEREIRA, 2013).

Como bem ensina Linhares (2014, p. 27):

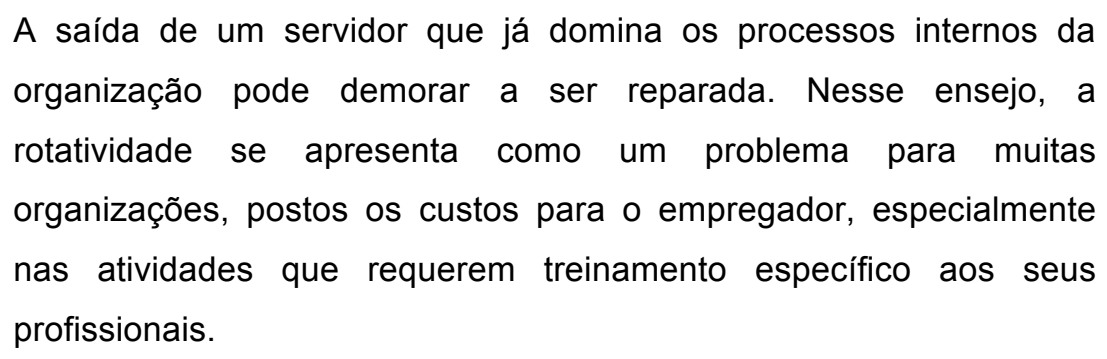

De acordo Maximiano (2015, p. 21) adverte que "[...] quando o nível de turnover é considerado alto, a organização pode estar em uma situação vulnerável, uma vez que sua força de trabalho poderá ser reduzida a inexperiência, acarretando novos custos".

\section{Metodologia}


No que compete à natureza da pesquisa, esta pode ser considerada uma pesquisa aplicada que é aquela que se objetiva em gerar conhecimentos para aplicações práticas dirigidas à solução de problemas específicos (GERHARDT; SILVEIRA, 2009).

Considera-se a pesquisa como prática, pois o pesquisador atua no Instituto de Previdência de Nilópolis e tem podido observar, ao longo dos anos, que o problema da rotatividade de pessoal demanda medidas urgentes para que os problemas decorrentes sejam sanados.

A pesquisa pode ser considerada explicativa, tendo em vista que este é um tipo de pesquisa em que os pesquisadores se preocupam em identificar algumas situações que contribuem com o registro, análise e interpretação de fenômenos, em busca de identificar causas, sendo uma pesquisa mais complexa, que busca verificar hipóteses causais, a qual usaremos como forma de observação.

Para a pesquisa bibliográfica foram consultadas informações obtidas em sites na internet como SciELO, Google acadêmico, cartilhas e manuais, livros, artigos, dissertações e teses relacionados com o tema abordado. Para a consulta foram abordados os seguintes descritores: rotatividade, serviço público, servidor público e soluções.

Será utilizado o método de pesquisa em campo com investigação e foram coletados a partir de entrevistas com servidores do Instituto de Previdência dos Servidores do Município de Nilópolis (fig. 1), Estado do Rio de Janeiro, que é um dos 13 municípios da Baixada Fluminense. Faz limite com os municípios de Mesquita, São João de Meriti e Rio de Janeiro. Tem uma área de $19.393 \mathrm{~km} 2$, sendo apenas $9.000 \mathrm{~km} 2$ em perímetro urbano. O município é composto de 157.986 habitantes, segundo censo de 2018.

Figura 1. Localização do Município de Nilópolis

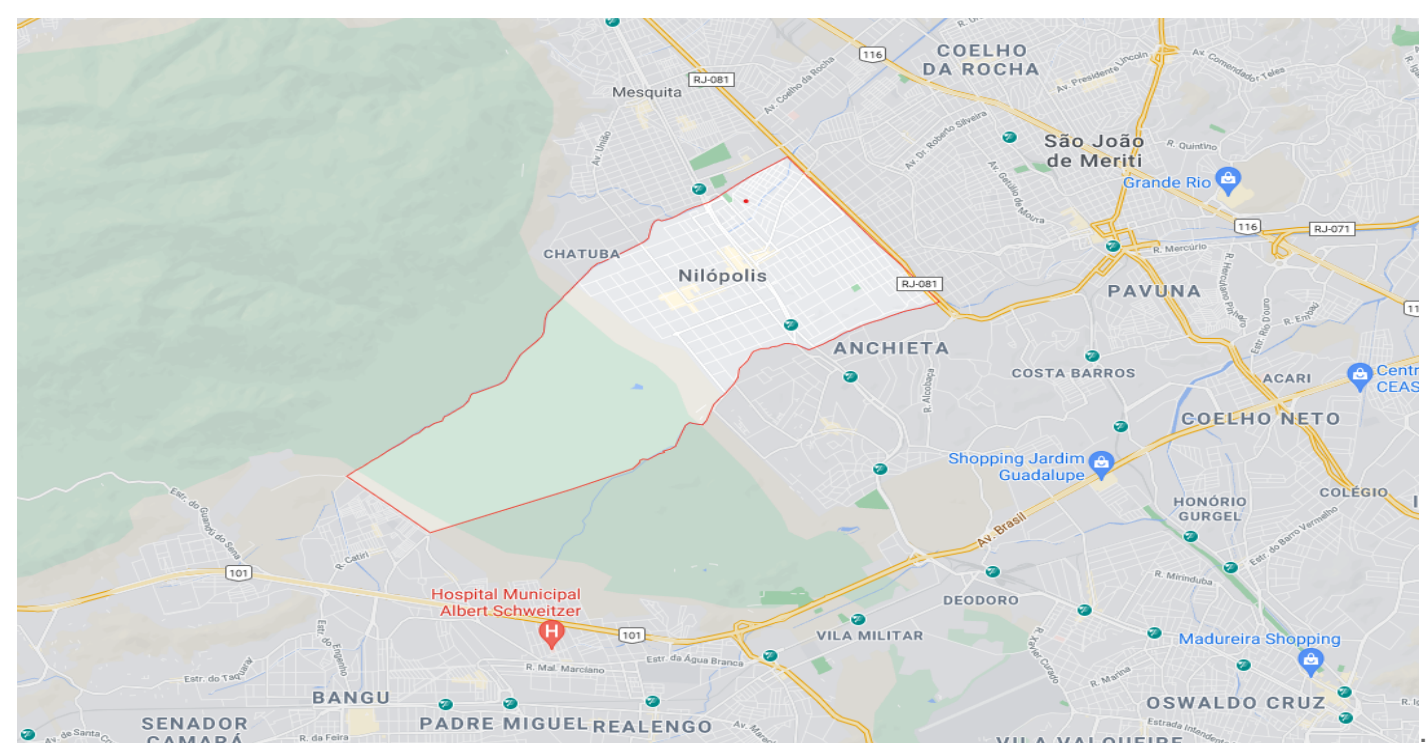

Fonte: Site Oficial da Prefeitura Municipal de Nilópolis (2019) 
A pesquisa realizada em campo trata-se de uma pesquisa de caráter pesquisa-ação, que conforme Koerich (2009, p. 718):

[...] visa fornecer aos pesquisadores e grupos sociais os meios de se tornarem capazes de responder com maior eficiência aos problemas da situação em que vivem, em particular sob a forma de estratégias de ação transformadora e, ainda, facilitar a busca de soluções face aos problemas para os quais os procedimentos convencionais têm contribuído pouco (KOERICH, 2009, p. 718).

$\mathrm{Na}$ pesquisa-ação, autores como Tripp (2005) informam que nesta é seguido um processo com o qual se possibilita a aprimorarão da prática a partir da oscilação sistemática que recai entre "agir no campo da prática e investigar a respeito dela. Planeja-se, implementase, descreve-se e avalia-se uma mudança para a melhora de sua prática, aprendendo mais, no correr do processo, tanto a respeito da prática quanto da própria investigação".

Para a pesquisa que foi realizada no Instituto de Previdência dos Servidores em Nilópolis, foram utilizados como instrumentos de coleta de dados a entrevista e a observação por entender que estes instrumentos foram os mais adequados ao tipo de pesquisa adotado pelos pesquisadores. Segundo explica Pádua (1997 apud PIANA, 2009, p. 179):

[...] a entrevista é um procedimento mais usual no trabalho de campo. Por meio dela, o pesquisador busca obter informes contidos na fala dos atores. Ela não significa uma conversa despretensiosa e neutra, uma vez que se insere como meio de coleta dos fatos relatados pelos atores, enquanto os sujeitos-objetos da pesquisa que vivenciam uma determinada realidade que está sendo focalizada (PÁDUA 1997 apud PIANA, 2009, p. 179).

Os sujeitos da pesquisa, objetos de observação e participantes da entrevista, foram os 18 servidores que atuam no instituto em análise. Todos aceitaram participar da pesquisa e a eles foi esclarecido que não sofreriam nenhum tipo de dano e não lhes seria pago nenhum valor monetário como compensação pela participação na pesquisa. Buscou-se junto aos servidores informações sobre a percepção destes acerca da influência da rotatividade de pessoal no Instituto de Previdência dos Servidores de Nilópolis. Para a entrevista foram estruturadas algumas perguntas para que o assunto não se perdesse. A pesquisa foi realizada durante os meses de janeiro, fevereiro e março do ano de 2019. 


\begin{abstract}
4 Resultados
Os resultados apresentados a seguir foram obtidos por meio de observação e entrevista com os 18 servidores que atuam no Instituto de Previdência dos Servidores do Município de Nilópolis. Destes servidores, 06 são efetivos e 12 são servidores comissionados, sendo 01 dos servidores efetivos, cedidos pela prefeitura (tab. 1).
\end{abstract}

Tabela 1. Servidores do Instituto de Previdência dos Servidores de Nilópolis-RJ

\begin{tabular}{|l|l|l|}
\hline \multicolumn{1}{|c|}{ N $^{\circ}$ DE SERVIDORES } & \multicolumn{1}{|c|}{ VínCULO EMPREGATícIO } \\
\hline $\mathbf{0 6}$ & $33,33 \%$ & Efetivos/concursados \\
\hline $\mathbf{1 2}$ & $66,66 \%$ & Cargo Comissionado \\
\hline
\end{tabular}

Fonte: Dados da Pesquisa (2020)

Como se pode perceber, a maior parte dos servidores que atuam no setor ocupam cargos comissionados, passiveis de demissão a qualquer tempo. Estes servidores atuam em uma autarquia dotada de autonomia financeira, administrativa e com capacidade jurídica própria (MAZZA, 2019).

Mas, como se pode perceber, no caso em análise isso não ocorre, o que termina por provocar uma grande rotatividade de pessoal 0 que se mostra prejudicial para $\circ$ desenvolvimento do trabalho a ser desempenhado, prejudicando, desse modo, não apenas o setor em si, mas também, os munícipes e servidores que precisam e merecem um serviço de qualidade.

Considerando que o regime próprio previdenciário dos servidores públicos municipal da prefeitura de Nilópolis-RJ é administrado por uma autarquia municipal, qual seja o Instituto de Previdência dos Servidores do Município de Nilópolis, a mesma precisa seguir as mesmas determinações legais apresentadas pelo Decreto-Lei $n^{\circ}$ 200, de 25 de fevereiro de 1967 e demais dispositivos regulamentam a administração pública brasileira tal como seus princípios expressos no texto constitucional, o que se verifica que não está acontecendo, tendo em vista que dos 18 servidores lotados, apenas 06 são servidores efetivos.

O caráter de autarquia do instituto é confirmado em seu regimento interno logo no segundo artigo da seguinte forma:

Art. $2^{\circ}$ - O PREVINIL é uma entidade autárquica, integrante da Administração Indireta do Poder Executivo Municipal, com personalidade jurídica de direito público interno, com autonomia financeira e administrativa, tendo por finalidade arrecadar, assegurar e administrar recursos financeiros e outros ativos para custear os proventos de aposentadoria, pensões e outros benefícios, concedidos e a conceder, a servidores públicos municipais e a seus dependentes (BRASIL, 2018, s/p). 
Apesar de não haver subordinação entre a administração pública indireta pela administração pública direta, apenas um controle ministerial como nos casos de desvios de finalidades ou outras infrações (MAZZA, 2019), com o Instituto de Previdência dos Servidores do Município de Nilópolis vem ocorrendo uma interferência política explicita quanto aos aspectos administrativos e organizacionais, uma vez que, o executivo municipal interfere em diversos setores do instituto nomeando funcionários.

Em relação às formas de provimentos dos servidores, este que deveria ser por meio de concurso público, onde o último ocorreu em 2008, sendo realizado pelo Instituto de Previdência dos Servidores do Município de Nilópolis. Desde o último certame diversos servidores foram lotados nas mais variadas funções dentro do instituto dentre estas, aquelas de responsabilidade como no controle interno indicando uma alta rotatividade de servidores impedindo que estes possam se adaptar e se especializarem para atuarem no controle interno do instituto de previdência municipal.

Ao se observar o Instituto de Previdência dos Servidores do Município de Nilópolis e modo como este é gerido percebe-se algumas falhas quanto aos procedimentos legais e estruturais da organização que, de forma direta, pode influenciar de forma negativa na especialização e a adaptação dos servidores do instituto de previdência municipal para atuarem nos departamentos da instituição.

Diante dessas observações, viu-se a necessidade de compreender melhor o que os servidores que atuam no setor acham da alta rotatividade de pessoal que tem ocorrido ao longo dos anos e de que modo eles acham que este problema pode ser resolvido. Os entrevistados foram questionados sobre o fato da alta rotatividade no setor afetar o desempenho das atividades. Mesmo que a maioria dos servidores esteja atuando em cargos comissionados, a grande maioria $(77,77 \%)$ afirmou que a alta rotatividade afeta negativamente o desenvolvimento das atividades e projetos do instituto e o atingimento de metas.

Tabela 2. A alta rotatividade de pessoal interfere negativamente no desempenho das atividades

\begin{tabular}{|l|l|}
\hline SIM & $\mathbf{7 7 , 7 7 \%}$ \\
\hline NÃO & $22,23 \%$ \\
\hline
\end{tabular}

Fonte: Dados da Pesquisa (2020)

Como se pode perceber, todos os servidores que atuam no Instituto de Previdência dos Servidores de Nilópolis tem conviç̧ão de que a alta rotatividade que vem ocorrendo na instituição tem prejudicado o desenvolvimento dos trabalhos e a prestação dos serviços públicos à sociedade.

Os servidores entrevistados foram questionados sobre possíveis soluções que poderiam ajudar a minimizar os problemas advindos da alta rotatividade. Nesse quesito as respostas dos servidores foram as seguintes: 
Tabela 3. Possíveis soluções que podem ajudar a minimizar os problemas advindos da alta rotatividade

\begin{tabular}{|c|c|}
\hline Respostas 1 & $\begin{array}{l}\text { Acho que a melhor solução seria promover concurso público para efetivar } \\
\text { servidores e desse modo diminuir a rotatividade. }\end{array}$ \\
\hline Respostas 2 & $\begin{array}{l}\text { Acredito que seria necessário contratar pessoas por sua competência e } \\
\text { qualificação para o desempenho das funções que a instituição necessita. }\end{array}$ \\
\hline Respostas 3 & $\begin{array}{l}\text { O rendimento diminui muito quando os servidores são trocados, por isso, acredito } \\
\text { que esse é um setor que não deveria sofrer interferência política para contratação } \\
\text { dos servidores. }\end{array}$ \\
\hline Respostas 4 & $\begin{array}{l}\text { Seria necessário contratar pessoas que tivesse, ao menos, noção das normas e } \\
\text { procedimentos internos do instituto, pois dessa forma, mesmo que haja uma alta } \\
\text { rotatividade, não haveria maiores problemas para dar continuidade às atividades. }\end{array}$ \\
\hline Respostas 5 & No momento não me vem nenhuma solução na cabeça. \\
\hline Respostas 6 & Prefiro não opinar. \\
\hline Respostas 7 & $\begin{array}{l}\text { Acredito que os cursos de capacitação para os novos servidores que irão } \\
\text { substituir os anteriores deveriam ser obrigatórios. }\end{array}$ \\
\hline Respostas 8 & Não vejo uma luz no fim do túnel para solucionar esse problema. \\
\hline Resposta 9 & Não gostaria de opinar. \\
\hline Resposta 10 & $\begin{array}{l}\text { Promover concurso público e só manter como cargo comissionado e de confiança } \\
\text { os setores de chefia como prevê a lei. }\end{array}$ \\
\hline Resposta 11 & Promover concurso público para efetivar os servidores que irão atuar no instituto. \\
\hline Resposta 12 & $\begin{array}{l}\text { Promover cursos de capacitação para os novos servidores antes de estes } \\
\text { ocuparem a posição para a qual tenham sido destinados. }\end{array}$ \\
\hline Resposta 13 & Não me acho capaz de dar uma solução plausível para solucionar esse problema. \\
\hline Resposta 14 & Promover cursos de capacitação e especialização. \\
\hline Resposta 15 & $\begin{array}{l}\text { Uso do manual que foi elaborado pelo Controle Interno para que os novos } \\
\text { servidores tenham um norte sobre como desempenhar da melhor maneira sua } \\
\text { função. }\end{array}$ \\
\hline Resposta 16 & Desculpe, prefiro não opinar. \\
\hline Resposta 17 & $\begin{array}{l}\text { Concurso Público e exigência de participação em cursos de especialização e } \\
\text { capacitação. }\end{array}$ \\
\hline Resposta 18 & $\begin{array}{l}\text { Colocar em prática o manual elaborado pelo controle interno para que os novos } \\
\text { servidores compreendam melhor as atividades que são desenvolvidas no Instituto } \\
\text { dos Servidores de Nilópolis. }\end{array}$ \\
\hline
\end{tabular}

Fonte: Dados da Pesquisa (2020) 
Antes de discutir as respostas dadas pelos servidores, é importante frisar que os 04 entrevistados que preferiram não emitir sua opinião quanto às possíveis soluções para minimizar o alto índice de rotatividade, são servidores comissionados.

Os entrevistados (04 deles) que disseram que a melhor opção seria a promoção de um concurso púbico, quando questionados sobre o referido assunto, responderam que não há previsão para o certame voltado a preencher as vagas no instituto. Importante esse ponto, pois as ações de recrutar e reter pessoas na administração pública é das mais desafiadoras, tendo em vista que "a investidura em cargo ou emprego público depende de aprovação prévia em concurso público de provas ou de provas e títulos, de acordo com a natureza e a complexidade do cargo ou emprego", nos termos da Constituição da República Federativa do Brasil, de 1988 (art. 37, I ao IV e de VIII ao IX, CR). Essa é uma das possíveis soluções para minimizar a rotatividade de pessoal no Instituto dos Servidores de Nilópolis.

A realização de um certame pelo Instituto de Previdência dos Servidores do Município de Nilópolis para contratação de servidores efetivos para os cargos atuantes na controladoria e demais departamentos também seria uma forma eficiente de se aperfeiçoar o trabalho neste setor com servidores motivados.

Quanto à resposta do servidor que alertou para a contratação de servidores competentes e qualificados, o que se observa é que a resposta veio ao encontro daquilo que foi encontrado como vantagem da rotatividade, proposta por autores como Sancho et al. (2012), Eckert et al. (2011) e Praça et al. (2012) que afirmam que quando ocorre à rotatividade tem-se a oportunidade de oxigenar novas ideias e competências quanto se agrega ao quadro servidores mais qualificados e com perfis e objetivos alinhados às ações institucionais.

No entanto, além de ser uma vantagem esse é também um desafio, pois é preciso muito planejamento e dimensionamento para lotar pessoas certas nos lugares certos (ECKERT, et al., 2011).

A resposta do servidor que afirmou que com a rotatividade há uma diminuição do rendimento há que se afirmar que o mesmo foi encontrado na revisão de literaturas promovida no presente estudo em que se identificou que essa é uma das desvantagens da rotatividade, pois o serviço público precisa buscar, cada vez mais, resultados positivos e satisfação dos usuários dos serviços públicos e, para isso, é preciso focar na profissionalização no desempenho com qualidade e produtividade (AMARAL; LOPES, 2014).

Quanto ao servidor que respondeu que é necessário que sejam promovidos cursos de capacitação (03 deles) para os servidores que vão substituir os anteriores, é preciso enfatizar que a capacitação por si só não é uma solução. Esse é apenas um aspecto técnico do trabalho, bem como o é o desempenho e a adequação ao ambiente físico. Quando se trata de rotatividade e da contratação de novos servidores deve-se levar em conta, além desses 
aspectos técnicos, as relações sociais, pois estas exercem uma forte influência sobre a rotatividade de pessoal (RODRIGUES, 2015).

Quanto aos 02 entrevistados que citaram o manual que foi elaborado pelo controle interno do instituto, vale dizer que o referido manual foi criado para ajudar aos novos servidores a compreenderem melhor suas novas funções. E, o mesmo, tem sido visto como solução para solucionar o problema da especialização e adaptação às normas e procedimentos da instituição prevista em seus manuais dos servidores lotados no Instituto de Previdência dos Servidores do Município de Nilópolis, acredita-se que a proposta de emenda constitucional a PEC n 45/2009 em que o controle interno seja considerado função essencial da administração pública e com órgãos permanentes e servidores que sejam organizados em carreiras específicas para sua atuação na forma prevista lei seria uma solução viável.

\section{CONSIDERAÇÕES FINAIS}

Ao propor a pesquisa, nos demos conta que em muitas organizações públicas brasileiras, as áreas que cuidam da gestão de pessoal ainda se dedicam principalmente às atividades relacionadas à folha de pagamento, benefícios da aposentadoria e afins, proposição de leis, regras e regulamentos, além de desenvolver algumas ações pontuais e emergenciais de treinamento e capacitação, sendo forma de ação reativa, respondendo quando acionadas pela demanda de outras áreas da organização, o que foge ao foco, relegando a segundo plano as atividades estratégicas como estabelecimento de objetivos e metas propostos, bem como planejamento de ações e políticas como contratação, capacitação e remuneração de pessoal.

Um dos principais empecilhos encontrados foi com relação à carência de estudos e políticas de gestão voltadas para os problemas acarretados pela rotatividade de pessoal. Mesmo sendo este um problema que traz muitos efeitos negativos para o processo organizacional.

Com o estudo foi possível perceber que as causas da rotatividade são as mais variadas possíveis e reconhecer os motivos que levam os servidores a saírem de seus postos é um ponto primordial para buscar melhorias para a organização e para a gestão do Instituto dos Servidores de Nilópolis. Para tanto é preciso que sejam promovidas políticas de valorização e de permanência desses profissionais como plano de cargos e salários.

Ainda que, com o estudo, tenha-se tentando propor soluções para o problema da rotatividade de pessoal no Instituto dos servidores de Nilópolis, sabe-se que há muito ainda a ser estudado sobre as causas, os impactos e sobre soluções viáveis para o problema da rotatividade no serviço público. Esse é um problema que precisa ser discutido com mais profundidade, principalmente, no que diz respeito aos custos operacionais e financeiros.

\section{REFERÊNCIAS BIBLIOGRÁFICAS}




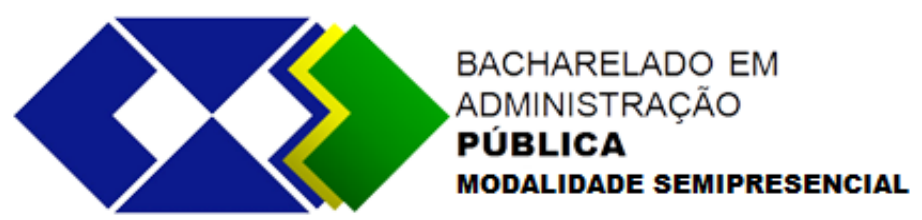

AMARAL, L. A.; LOPES, S. M. A. Rotatividade de Pessoal no Serviço Público Federal: um estudo de caso na UFPE. In: VII Congresso CONSAD de Gestão Pública, 2014, Brasília. Anais... Brasília: [s.n.], 2014.

Araújo, C. A. (2006). Bibliometria: evolução histórica e questões atuais. Em Questão, 12(1), p. 11-32.

BERGUE S.T. Gestão de Pessoas em Organizações Públicas. Caxias do Sul: EDUCS, 2007.

BRASIL. Constituição Federal de 1988. Brasília-DF, 1988.

PEC 045/09. Proposta de Emenda Constitucional n. 45, de 2009. Brasília-DF, 2009.

CAMPOS, C. V. D. A.; MALIK, A. M. Satisfação no trabalho e rotatividade dos médicos do Programa de Saúde da Família. RAP, Rio de Janeiro, v. 42, n. 2, p. 347- 3682018.

CHIAVENATO, Idalberto. Recursos humanos. 3. ed. São Paulo: Atlas, 2002.

COBÊRO, C.; PEREIRA, T. S. Análise das Causas da Rotatividade de Colaboradores em uma Indústria Têxtil de Pequeno Porte no Interior de São Paulo. In: X Simpósio de Excelência em Gestão e Tecnologia - SEGeT, 2013. Anais.... [S.I.]: [s.n.]. 2013.DEPARTAMENTO INTERSINDICAL DE ESTATÍSTICA E ESTUDOS SOCIOECONÔMICOS. Rotatividade e flexibilidade no mercado de trabalho. São Paulo: DIEESE, 2019.

ECKERT, A. As Motivações e os Reflexos do Turnover em Termos Contábeis e Econômicos numa entidade sem fins lucrativos do município gaúcho de Caxias do Sul. In: XIII Convenção de Contabilidade do Rio Grande do Sul, 2011, Caxias do Sul. Anais... Caxias do Sul: [s.n.]. 2011.

El-Maamiry, A.A. \& Ghauri, M.A. (2013). Measuring information quality: Concerns on the use of bibliometric studies. International Journal of Information Dissemination and Technology, 3(4), 274-278.

GARCIA, R. C.; \& ARAÚJO, J. M. (2012). Os princípios da Administração Pública no Sistema Jurídico Brasileiro. Revista Âmbito Jurídico. São Paulo.

GERHARDT, T. E.; SILVEIRA, D. T. Métodos de pesquisa. Coordenado pela Universidade Aberta do Brasil - UAB/UFRGS e pelo Curso de Graduação Tecnológica - Planejamento e Gestão para o Desenvolvimento Rural da SEAD/UFRGS. - Porto Alegre: Editora da UFRGS, 2009.

KOERICH, M. S. Pesquisa-ação: ferramenta metodológica para a pesquisa qualitativa. Rev. Eletr. Enf. [Internet], 2009.

LINHARES, L. M. Rotatividade no serviço público: estudo de caso do cargo de Analista de Planejamento e Orçamento. 2014. 100 f. Dissertação (Mestrado em Administração) Universidade de Brasília. Brasília: UNB, 2014.

MAXIMIANO, R. L. D. S. Rotatividade de pessoal: análise na empresa Interlagos na cidade de Mossoró/RN. 2015. 70 f. Relatório Final de Curso (Graduação em Administração) Universidade do Estado do Rio Grande do Norte. Mossoró: UERN, 2015.

MAZZA, A. (2019). Manual Direito Administrativo. 9 ed. Saraiva. Rio de janeiro - RJ, 
MEDEIROS, C. R. G. et al. A rotatividade de enfermeiros e médicos:um impasse na Implementação da Estratégia de Saúde da Família. Ciência \& Saúde Coletiva, n. 15 (Supl. 1), p. 1521-1531, 2010.

Moynihan, D.P., \& Pandey, S.K. (2008). The ties that bind: social networks, personorganization value fit, and turnover intention. Journal of Public Administration Research and Theory, 18(2), 205-227.

PIANA, M. C. A construção do perfil do assistente social no cenário educacional. São Paulo: Editora UNESP; São Paulo: Cultura Acadêmica, 2009.PRAÇA, S.; FREITAS, A.; HOEPERS, B. A rotatividade dos servidores de confiança no governo federal brasileiro, 2010-2011. Novos estudos - CEBRAP [online], n. 94, p. 91-107, 2012.RODRIGUES, G. B. Rotatividade de Pessoal na Universidade Federal de Pernambuco. 2015. 159 f. Dissertação (Mestrado Profissional em Gestão Pública para o Desenvolvimento do Nordeste) Universidade Federal de Pernambuco. Recife: UFPE, 2015.

SANCHO, L. G. Rotatividade na Força de Trabalho da Rede Municipal de Saúde de Belo Horizonte, Minas Gerais: um estudo de caso. Trab. Educ. Saúde, Rio de Janeiro, v. 9, n. 3, p. 431-447, 2011/2012.

TRIPP, D. Pesquisa-ação: uma introdução metodológica. Educação e Pesquisa, São Paulo, v. 31, n. 3, p. 443-466, set. /Dez. 2005. 